stomach die for want of early surgical interference where the case was seen immediately after the perforation-i.e., if we judge from the history which was absolutely typical, a large dose of morphia administered and the friends recommended to wait. The diagnosis was verified post mortem. I think the surgeon cannot plead too strongly that morphia should be withheld until he has seen the case, for I hold that the patient will have a far better chance and the surgeon, too, is far more likely to make a correct diagnosis, which means that his treatment-operative interference-is more likely to be effectual.

Gastro-jejunostomy was performed here for the following reasons, especially (1) because of the considerably narrowed pyloric orifice; (2) the presence of ulceration of the duodenum ; and (3) the persistent discomfort felt even after a restricted diet.

\section{HUNTINGDON COUNTY HOSPITAL.}

$\triangle$ CASE OF ADDISON'S DISEASE, WITH HYPERPYREXIA. (Under the care of Mr. H. LUCAS.)

ADDISon's disease is usuall 7 unaccompanied by any elevation of temperature, and therefore the following case is of interest. The very remarkable temperatures recorded would in themselves suggest doubts as to their genuineness, especially as the pulse-rate was not increased, but care seems to have been taken to eliminate this source of error. For the notes of the case we are indebted to Mr. Jehan M. Barlet, house surgeon.

A woman, aged 39 years, was admitted into the Huntingdon County Hospital on April 2nd, 1902, complaining of great pain in the region of the kidneys with marked bronzing. The patient's brother died two years ago from phthisis, five other brothers being alive and well. She was perfectly well until August, 1898, when she was suddenly seized with acute pain in the back after a hard day's washing. This pain radiated round to the epigastric region and was accompanied by diarrhœe and vomiting and a feeling of languidness and later patches of yellow pigmentation appeared which became gradually darker in colour. She was in hospital in 1898 but went out fairly well and had been able to get about until August, 1901, when the pain increased, as also did the pigmentation, and there was a recurrence of the diarrhoea and vomiting.

On admission the patient was very bronzed, especially about the nipples, axillæ, and face. There was great pain an pressure over the region of the kidneys, especially upon the right side, where there was a tender spot anteriorly, corresponding with the right kidney. She had slight attacks of headache and dizziness occasionally. All the other organs were normal. The urine was normal. There were no cerebral symptoms. The bowels were very constipated and there was no vomiting. Now comes the extraordinary part of the case. On admission her temperature was $99.6^{\circ} \mathrm{F}$. but this gradually rose by morning rises and evening remissions to $103.4^{\circ}$ on April 8th, when she was put on a four-hourly chart which showed a temperature of $105.6^{\circ}$ at $10 \mathrm{P}$.M. The temperature then kept between $101^{\circ}$ and $103^{\circ}$ until 2 A. M. on the 10th, when she had a rigor with a temperature of $109^{\circ}$, followed by profuse sweating and a fall to $100 \cdot 2^{\circ}$. From then till the present time (June 14th) the following temperatures have been recorded: $107^{\circ}, 12$ times; $108^{\circ}$, three times; $109^{\circ}$, seven times; $110^{\circ}$, six times; $111^{\circ}$, once ; and $111.6^{\circ}$ once. These temperatures were verified by being taken in the rectum, so preventing the possibility of "faking." Another interesting point is that when these e'evations of temperature occurred, which, by the way, was usually at 10 P. M. or 2 A.M., there was no increase in the pulse rate-for instance, in the highest temperature at present recorded in her case the pulse-rate was 66 to the minute and this temperature fell to $100^{\circ}$ in half an hour. On questioning her as to her feelings she said that she felt as if she were going to die but she felt no pain anywhere.

Remarks by Mr. BARLET. - The question arises as to the cause of these elevations of temperature. I think without doubt that they are due to some nervous influence, but whether they are caused by irritation of the semilunar ganglion and the sympathetic system, thus acting upon the thermogenetic centre, $\mathbf{I}$ am not prepared to state and should very much like to hear some opinions on this subject. I have to thank Mr. Lucas for permission to publish this case.

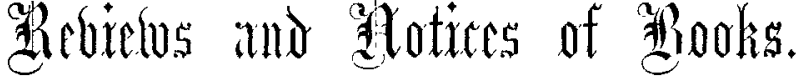

Nothnagel's Encyclopedia of Practical Medicine (Diphtheria, Measles, Scarlatina, and German Measles). Edited, with additions, by WILliam P. NORThuP, M.D. Authorised translation from the German under the editorial supervision of ALFRED STENGEL, M.D. London and Philadelphia: W. B. Saunders and Co. 1902. Pp. 672.

THIS volume is distinguished from others of the series which have so far been published by the substitution of an article on Diphtheria by an American author-namely, Dr. W. P. Northup-in place of a translation of the original article as it stands in the German edition. This departure from the course heretofore pursued has been necessitated by an arrangement entered into by the German author to issue a translation of his article independently of the series. Apart from auy sentimental regrets which may attach to a proceeding which severs the traditions of Nothnagel's Encyclopedia on the score of efficiency and completeness there is no reason whatsoever to deplore the change. Dr. Northup is an acknowledged authority on the subject of diphtheria, a writer of experience and erudition, and his well-known association with Dr. Joseph O'Dwyer in the practical development of the method of intubation necessarily imparts a distinctive interest to this article and justifies the honourable inclusion of his name on one of the title pages of a work which among those of other contributors contains the names of von Jürgensen, Immermann, von Liebermeister, Ehrlich, and Stiker.

Confining ourselves for the present to the consideration of Dr. Northup's article we may proceed at once to the observation that the method and style which characterise his contribution are thoroughly representative of the best examples of American authorship. Free from the hidebound conservatism which detracts so largely from the value of much of our own British medical literature, steadied by the weight of German philosophic thought, and.brightened with the leaven of transatlantic originality, this article on diphtheria is not only practically and substantially sound, but also delightfully illuminating and suggestive reading. After briefly epitomising the history of the disease the author immediately proceeds to the consideration of the various etiological factors which determine its development. The bacteriology of diphtheria, in conformity with the importance and interest which attach to this side of the question, occupies the position of honour and the lion's share of the pages devoted to the subject of pathogenesis. As the result of the early studies of Klebs, Löffler, and later of the researches of Roux and Yersin, the specificity of the Klebs-Löffer bacillus is considered by Dr. Northup to have been established beyond a doubt, for the reason that it has been repeatedly proved to fulfil the conditions required of all organisms if they are to be accepted as specific excitants of infective disease. The respective claims of the monistic and dualistic schools are considered in some detail and as representatives of the former school of thought Gorham and Westbrook are freely quoted, and their work on the morphological characteristics of diphtheria bacilli is fully described and illustrated by a plate. Westbrook, whose work has been extended and confirmed by Gorham, divides all diphtheria bacilli into three groups-the granular, barred, and even-staining. Their united observations show that, as the result of the examination of 2375 cultures taken from persons who were healthy, whether disposed to diphtheria or not, the changes from the solid type develop under the influence of the body fluids of persons immune or becoming so. Interesting as these researches are from the morphological side, they contribute little to out 